\title{
OPTIMISE YOUR EFFICIENCY AND THRIVE
}

Be sure to visit stands Q05 and R09 at this year's BDTA Dental Showcase to see how Software of Excellence's THRIVE programme can optimise the efficiency of your practice.

Using the powerful data within EXACT, THRIVE provides up-todate business information that helps develop specific strategies to improve practice efficiency. It does this by streamlining administrative duties and highlighting shortfalls in performance. Increasing effectiveness in ten Key Performance areas, including recalls, FTA management, forward cover of appointment book and chairside use, has delivered some outstanding individual results. More than 200 practices have now benefited from the six-month programme, and there has been an average increase of $£ 100,000$ per practice in gross revenues.

Software of Excellence (SoE) is now able to use the data collected from THRIVE practices to formulate a series of standards against which the performance of individual practices can be rated. Using their 'What If' calculator, SoE can predict what the future might hold for your practice if certain key management areas are improved. www.soeidental.com

\section{COMMUNICATION TOOLS AND PANORAMIC IMAGING}

Visit Carestream Dental at BDTA Dental Showcase and find out how the latest advances in dental software and equipment can dramatically improve patient care and practice profitability:

- CS R4 communication tools: new launch supporting dentists to communicate effectively with their patients using Carestream Dental products and services

- CS 8100: new launch offering the simplicity of compact panoramic imaging.
Talk to the knowledgeable team about the huge range of marketleading solutions on offer. Innovations from Carestream Dental are easy to use and blend seamlessly into practices of all shapes and sizes.

Discover what you can achieve with faster processes, enhanced accuracy and true integration for an impressive modern practice that gives patients the 'wow' factor.

Carestream Dental will be on stand C08 at Showcase or call 0800169 9692. www.carestreamdental.co.uk

\section{NEW GENERATION AIR DRYER}

The Gast Group - a member of the IDEX Corporation's health and sciences division - will be using this year's BDTA Dental Showcase Exhibition to support its network of national and regional dental distributors and launch its new generation JUN-AIR iQdryer desiccant air dryer to the UK and Ireland dental market.

The Gast Group's focus is to ensure that product and service levels available to dental distributors reflect JUN-AIR's position as the premium compressor and compressed air accessory brand and that they continue to support their customers with a service that matches the quality of their compressors. The company will listen to its customers' needs and ensure that sales, service and stock levels meet the needs of the distribution network in the UK and Ireland.

JUN-AIR will also be using its stand to launch the iQdryer - a new high purity, heatless desiccant air dryer that, using a patented design that combines the filter and desiccant dryer in a single cartridge, eliminates the need for external filters and drains and reduces the energy consumed by compressors by reducing pressure drop.

For further information on JUNAIR's dental range, including the new iQdryer, visit www.jun-air.com and stand T01 at Showcase. 